\title{
De norske fjelde - rodløse realiteter
}

Af Peter Japsen, Johan M. Bonow, James A. Chalmers og Erik S. Rasmussen, De nationale geologiske undersøgelser for Danmark og Grønland (GEUS)

I GeologiskNyt 5/2007 opsummerede vi et væld af oplysninger, der viser, at de norske fjelde har været udsat for vertikale bevægelser i kilometer-skala i Kænozoikum, og at fjeldene først har nået deres nuværende højder i Neogen. Søren B. Nielsen (SBN) kommenterer i GeologiskNyt 1/2008 vores indlæg, men kommer desværre ikke med yderligere argumenter for sin hypotese om, at de norske fjelde er resterne af den bjergkæde, der blev dannet under den kaledonske kollision mellem Baltica og Grønland for mere end 400 millioner år siden. Derimod skaber SBN usikkerhed om simple kendsgerninger, der er af afgørende betydning for vurderingen af de norske fjeldes alder og struktur.

Vi vil derfor i det følgende uddybe vores kritik af SBNs påstande for at undgå at "uskyldige loesere bliver ført bag lyset".

\section{Isostasi og Norges fjelde}

I følge SBNs model har de norske fjelde en skorperod, som er resterne af den, der blev dannet under den kaledonske kollision, og det er underskuddet af masse i denne rod,
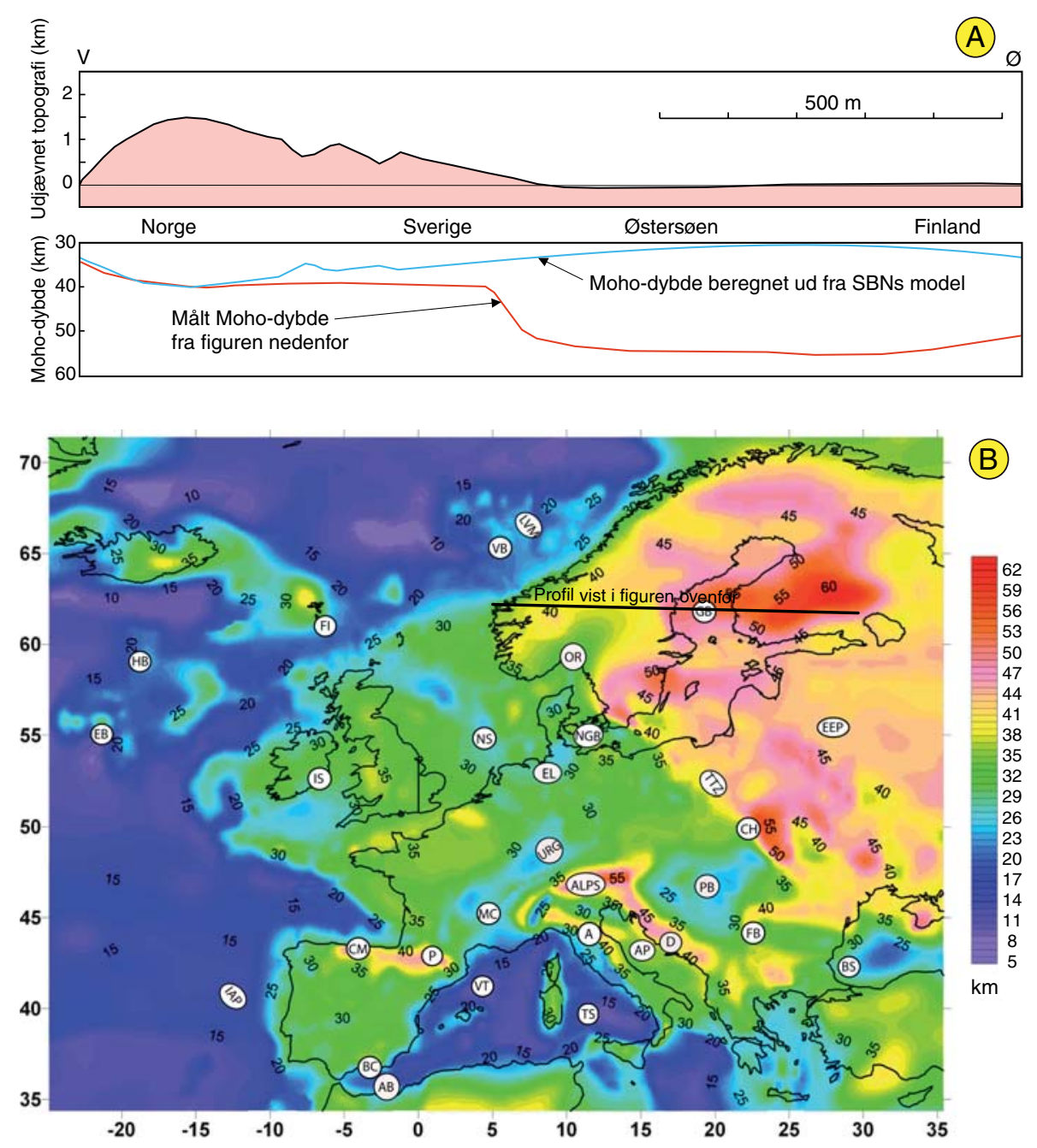

som holder fjeldene oppe som resultat af isostatisk uplift. SBNs hypotese er let at teste: Figuren nedenfor (A) viser et profil på tværs af Skandinavien og Finland, hvor dybden til Moho (tykkelsen af skorpen) er indtegnet, så den passer med topografien som forudsagt af SBNs model (blå kurve): Moho skulle således ligge ca. $40 \mathrm{~km}$ under de norske fjelde og $i$ en noget mindre dybde mod øst, hvor der ikke er fjelde. Men vi har også indtegnet de målte Moho-dybder langs profilet baseret på kortet i (B) (figuren nederst på denne side), der viser de seneste publicerede Moho-dybder under Europa (rød kurve): Moho ligger ganske rigtigt omkring $40 \mathrm{~km}$ under de norske fjelde, men dybden stiger til mere end $40 \mathrm{~km}$ under Sverige, til over $50 \mathrm{~km}$ under Østersøen og til mere end $60 \mathrm{~km}$ under det østlige Finland. Hvis SBNs

(A) Ifølge SBNs hypotese holdes de norske fjelde oppe af en let skorperod. Vi har brugt SBNs tal for skorpens massefylde på 2,8 $\mathrm{kg} / \mathrm{m}^{3}$ og den underliggende kappes på 3,4 $\mathrm{kg} / \mathrm{m}^{3}$. Ud fra antagelsen om Airy isostasi vil denne densitetskontrast føre til en jordoverflade, hvis højde over havniveau er 0,21 gange forskellen mellem dybden til Moho; $f x$ vil en skorperod på $10 \mathrm{~km}$ føre til højder på 2,1 km. Vi har anvendt denne hypotese til at beregne, hvordan Mohos topografi skulle se ud baseret på SBNs hypotese langs et profil fra Norge til Finland (blå kurve). Sammenligning med den faktiske Moho-topografi (rød kurve) viser, at SBNs hypotese ikke resulterer i en korrekt prognose.

(B) Kort over målte dybder til Moho under Europa. Moho under Skandinavien og det nordøstlige Europa (svarende til Balticakontinentet før den kaledonske orogenese) er overalt markant dybere end under resten af Europa på noer skorperødderne under de kcenozoiske bjerge ( $f x$ Pyrenceerne og Alperne). Den markante Moho-dybde under Baltica svarer på ingen måde til overfladetopografien. Bemoerk, at skorpetykkelsen under det sydlige Norge ikke er scerligt stor, og at den udtyndede skorpe under Oslo-graven og vest for Norge bevirker, at skorpen under de højeste fjelde udgør et lokalt maksimum. (Grafik: Kortet er fra Tesauro et al. 2008 og er her genoptrykt med forfatternes tilladelse) 


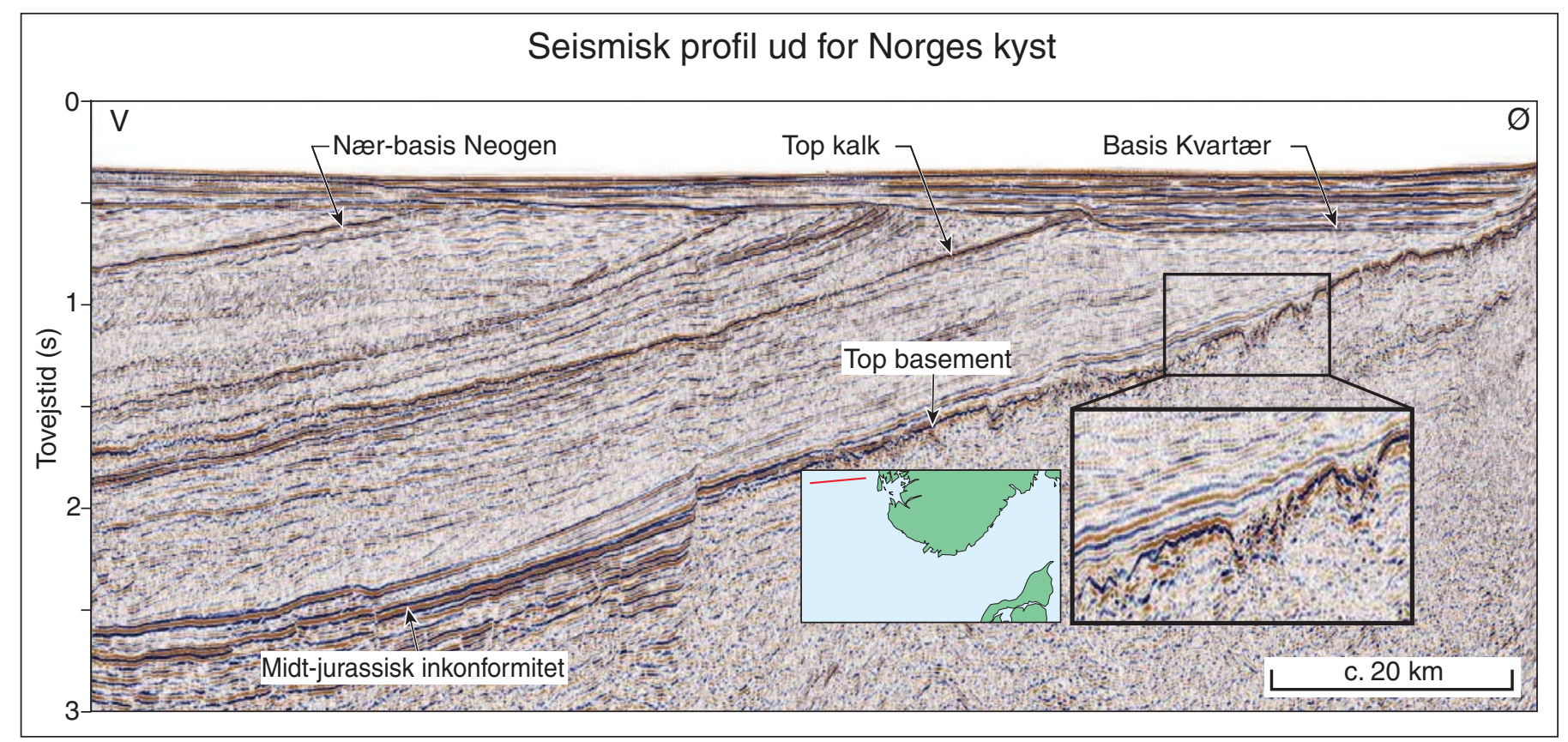

Irregulcer grundfjeldstopografi daekket af øvre-jurassiske sedimenter afbildet på seismisk profil ud for Norges kyst. Den irregulcere topografi skyldes forvitring af grundfjeldet langs sprokker og forkastninger, da grundfjeldet var blottet $i$ Jura, hvor klimaet var varmt og fugtigt. Umiddelbart øst for profilet er grundfjeldet i dag blottet, og den irregulcere topo-grafi kan nemt erkendes som et småbakket landskab, der vidner om landformernes dannelse for millioner af år siden. Når disse former er bevaret i dagens landskab, skyldes det, at grundfjeldet har varet beskyttet under de samme sedimenter, som kan ses på det seismiske profil, indtil landhoevning førte til erosion og gen-eksponering af grundfjeldet. Bemcerk den markante afskcering af de sedimentcere lag ind mod Norge, som tyder på, at jordskorpen er blevet hoevet så sent, at også basis af de neogene aflejringer er blevet afskåret. (Grafik: Det seismiske profil er venligst stillet til rådighed af Lars Nørgård Jensen, StatoilHydro)

hypotese var korrekt, ville de højeste bjerge i Skandinavien ligge i Finland! At dette ikke er tilfældet, viser, at der er noget alvorligt galt med SBNs hypotese, og at der ikke er nogen skorperod under de norske fjelde.

At SBNs model ikke passer med virkeligheden, burde ikke overraske, da det længe har været kendt, at eklogit fra rødderne af det kaledonske orogen i dag er blottet ved jordens overflade i det vestlige Norge. Når kollisionsbjerge vokser, skaber de en rod, som bliver presset ned i Jordens kappe (sådanne rødder kan ses på kortet $\mathrm{i}$ (B) figuren nederst på foregående side) under de kænozoiske bjerge, fx Pyrenæerne, Alperne og Appeninerne). Ved tilstrækkelig stor dybde bliver gnejs omdannet til eklogit - men først ved tryk og temperatur der svarer til dybder på mere end $50-60 \mathrm{~km}$. Det er veldokumenteret, at de kaledonske eklogitter blev bragt nærmere til overfladen på grund af ekstension og rotation af skorpeblokke, da de kaledonske bjerge kollapsede i Devon. Efterfølgende erosion bragte eklogitterne helt op til jordoverfladen.

Hvis SBNs hypotese trods dette havde været korrekt, skulle der også være høje bjerge i det sydlige Danmark og i det nordlige Polen. Kollisionen mellem Baltica og Grønland var nemlig ikke den eneste, der fandt sted under den kaledonske bjergkædedannelse. Der fandt også en kollision sted mellem Balticas sydlige flanke og kontinentet Avalonia, som førte til dannelse af endnu en kaledonsk bjergkæde. Resterne af disse bjerge er i dag begravet under tykke sedimentlag, hvilket ikke er muligt at forklare ud fra SBNs hypotese om, at rødderne fra det kaledonske orogen stadig findes.

De høje fjelde i det nordatlantiske område er imidlertid ikke begrænset til de områder, hvor den kaledonske deformation fandt sted. Ganske vist findes kaledonske bjergarter i højtliggende områder i både Østgrønland, Skotland og Skandinavien, men det samme gælder for prækambrisk grundfjeld i Grønland og Skandinavien. Der er endda sen-mesozoiske og palæogene bassiner på både Øst- og Vestgrønland, hvor marine fossiler findes i mere end $1 \mathrm{~km}$ over havniveau. Der er med andre ord ingen korrelation mellem vor tids høje fjelde og kaledonsk grundfjeld.

\section{Landskabets hovedtræk}

SBN gemmer sig bag et røgslør af retorik, når han påstår, at ethvert landskab har alderen nul ("fordi der altid er et sandkorn, der lige har flyttet sig"). Der er vel næppe nogen, der vil bestride at Vejle Fjord eller Sognefjorden primært er udformet af glaciale processer? Det er klart, at det er muligt at vurdere landskabets udviklingshistorie ud fra dagens karakteristika. I øvrigt er det interessant, at SBN falder i sin egen fælde, når han påstår, at ethvert landskabs alder er nul, samtidig med at dagens norske fjelde skulle stamme fra den kaledonske orogenese.

Det er veldokumenteret, at hovedtrækkene i det kuperede landskab langs den svenske vestkyst skyldes mesozoisk forvitring, men også omkring Oslo og Trondheim findes der tilsvarende landskaber, selvom de ikke er blevet nøjagtigt karteret. SBN påpe- ger rigtigt, at der ikke findes bevarede mesozoiske sedimenter i Sydnorge, men flint og rester af Mesozoiske sedimenter, der er bevarede i nedforkastede positioner, viser, at den nuværende grundfjeldsoverflade er meget tæt på den mesozoiske overflade, fx ved Oslo, Bergen og Trondheim. Denne tolkning støttes af seismiske profiler ud for Norges kyst, der viser, at grundfjeldets overflade er kuperet og dækket af Jura-Kridt-sedimenter (figuren ovenfor). Desuden viser figuren ovenfor, at Jura-Kridt-sedimenterne må have været udbredt langt ind over de nuværende landområder.

At mesozoisk forvitring spiller en stor rolle i Norge, er for nylig blevet dokumenteret af Olesen et al. (2007). I Oslo-området har vandførende svaghedszoner nemlig kostet det norske samfund milliarder af kroner i forbindelse med tunnelbyggeri i Oslo-området. Forfatterne finder, at de strukturelle svaghedszoner, der indeholder lermineraler, skyldes kemisk forvitring i sprækkezoner under subtropiske betingelser i Sen Trias, Jura og Tidlig Kridt. Når der eksisterer mesozoiske træk i landskabet, skyldes det, at grundfjeldet dengang udgjorde bunden af en dybtgående forvitringszone, som man kender det fra troperne.

I dag er der kun kaolin-rester tilbage af forvitringsmaterialet, mens den irregulære overflade af det uforvitrede grundfjeld fremstår som bakker, der kun er bevarede, fordi de har været begravet under et tykt sedimentdække, indtil grundfjeldet igen blev blottet.

I modsætning til det kuperede landskab 
langs kysten, er de vidtstrakte vidder typiske for det norske højfjeld. Sådanne højtliggende plateauer, der er gennemskåret af dybe dale, udgør et karakteristisk træk ved fjeldene langs mange passive kontinentrande over hele Jorden. Her har naturen nedfældet sin historie med meget store bogstaver, og den der ikke kender dette alfabet, har ikke andet end sine egne forestillinger og computerprogrammer at holde sig til. Højsletterne volder da også SBN mange problemer - måske findes de slet ikke, måske ser det bare ud, som om de er der, måske er de resultatet af glacial erosion - og han forholder sig slet ikke til den kendsgerning, at sådanne plateauer findes overalt på Jorden, og at deres tilstedeværelse og nuværende højde er uafhængig af, om et område har været nediset eller ej.

Disse vidtstrakte flader, der kan kortlægges over hundredvis af kilometer og afskærer bjergarter af forskellig alder og styrke, må være dannet ved fluvial erosion til veldefinerede basisniveauer. De norske vidders regionale udbredelse betyder, at havniveau er det mest sandsynlige basisniveau. Denne konklusion bestyrkes yderligere af, at sedimenterne offshore viser, at de nuværende landområder befandt sig i havets umiddelbare nærhed siden slutningen af Jura. Når disse erosionsflader i dag findes langt over havniveau, skyldes det landhævning, efter at fladerne er blevet dannet. Landhævningen fører til indskæring af floddale, og derfor vil fladerne hurtigt blive gennemskåret og til slut destrueret. Derfor tyder højtliggende og velbevarede erosionsflader på en relativt ung landhævning. Det er disse kendsgerninger og observationer, som ligger til grund for vores vurdering af de store træk $\mathrm{i}$ landskabsudviklingen i Norge, sådan som vi præsenterede dem i GeologiskNyt 5/2007:

1. De vidtstrakte vidder domineres af en let hældende flade, der ligger i ca. 1.000 meters højde over havniveau, samt rester af yderligere flader over dette niveau.

2. Disse plateauer adskiller sig markant fra et kuperet relief, der må være af mesozo-isk alder, der ligger som et hældende plan på et lavere niveau langs højsletternes kanter.

3. Dette kuperede relief afskæres af vidderne, der derfor må være dannet senere end det kuperede relief. Da de vidtstrakte flader er udviklet over områder med forskellige geologiske forhold, er det muligt at konkludere, at vidderne må være dannet ved erosion styret af en erosionsbasis nær havniveau. Desuden må fladerne være dannet $\mathrm{i}$ Kænozoikum.

4. Efterfølgende er sletterne hævet til deres nuværende højder, mens de gamle forvittringsflader er blevet blottet, efter at de beskyttende dæklag er blevet borteroderet.

Dette overordnede forløb viser, at de norske fjelde først har opnået deres nuværende højder sent i Kænozoikum, og at de på ingen måde er resterne af den kaledonske bjergkæde. Men det er kun muligt at ridse udviklingen op i grove træk, da der kun foreligger en meget foreløbig kartering af såvel de re-eksponerede som de nye erosionsflader, der udgør et komplekst system i det sydlige Norge.

\section{Kvantitative og kvalitative udsagn}

Vi arbejder som detektiver i sporene efter naturens drama. Vi har søgt at rekonstruere det geologiske hændelsesforløb på basis af observationer, så vi kan indsnævre listen over, hvem der kan have været de skyldige - hvilke processer der kan have dannet de norske fjelde. Som vi her har redegjort for, kan vi fx udelukke at fjeldene blev dannet under den kaledonske orogenese, og vi kan fastslå, at den nuværende topografi først opstod i Kænozoikum.

SBN har derimod valgt at gå den modsatte vej, idet han har opstillet hypoteser, som han vil teste. Disse hypoteser klarer imidlertid ikke at blive testet mod allerede eksisterende data og kan derfor tilbagevises (og dermed spare SBN for en masse besvær), fx bæres de norske fjelde ikke oppe af en skorperod, og vidderne er ikke dannet af glaciale processer. Men fysikere er trænet $i$ at arbejde med kvantitative udsagn og er derfor tilbøjelige til at betragte beregninger fra en computer-model som mere pålidelige end kvalitative feltobservationer. Kan man fx på en computer simulere, at glacial erosion $\mathrm{i}$ grundfjeld kan producere relativt plane flader - på trods af at årtiers glacialmorfologisk forskning viser, at glacial erosion øger eksisterende relief-forskelle - så vil nogle fysikere ufortrødent gå videre med de numeriske beregninger.
Det er en almindelig videnskabelig fremgangsmåde, som SBN benytter sig af, men den indebærer, at man begrænser sig til at teste, hvad man kan forestille sig. Når man så desuden på forhånd udelukker de observationer, som ikke passer ind i ens verdensbillede, ender man som de skolastikere, der nægtede at se i Gallileis kikkert for ikke at blive konfronteret med den ubehagelige sandhed, at Jupiter har måner, der ikke roterer om Jorden.

Vi påstår ikke, at alle detaljer om landskabsudviklingen i Sydnorge er kendt, men vi præsenterer simple kendsgerninger og fremlægger en overordnet model, som forklarer områdets geomorfologiske hovedtræk, idet vi støtter os til detaljerede studier af reliefudviklingen i Sydsverige. Vi er klar over, at disse hovedtræk for landskabets udvikling endnu ikke kan forklares med fysiske modeller, men måske er det på tide at revidere modellerne, så de kommer til at svare til virkeligheden.

\section{Referencer:}

Andersen, T.B. \& Jamtveit, B. 1990. Uplift of deep crust during orgenic extensional collapse - a model based on field studies in the Sogn-Sunnefjord region of western Norway. Tectonics 9, 1097-1111.

\section{Fossen, H., Mangerud, G., Hesthammer,} J., Bugge,T. \& Gabrielsen, R.H. 1997. The Bjorøy Formation: a newly discovered occurrence of Jurassic sediments in the Bergen Arc System. Norsk Geologisk Tidsskrift 77, 269-287.

Johansen, E. 1955. Flintfunn och flinttyper fra Öst-Norge. Norsk Geologisk Tidskrift, 35.

Johansson, M., Olvmo, M., Lidmar-Bergström, K. 2001. Inherited landforms and glacial impact of different palaeosurfaces in southwest Sweden. Geografiska Annaler $83 A, 67-89$

Lidmar-Bergström, K., Ollier, C.D. \& Sulebak, J.R. 2000. Landforms and uplift history of southern Norway. Global and Planetary Change 24, 211-213.

Olesen, O., Dehs, J.F., Ebbing, J., Henriksen, H., Kihe, O. \& Lundin, E. 2007. Aeromagnetic mapping of deep-weathered fracture zones in the Oslo Region - a new tool for improved planning of tunnels. Norwegian Journal of Geology 87, 253-267.

Sommaruga, A. \& Boe, R. 2002: Geometry and subcrop maps of shallow Jurassic basins along the Mid-Norway coast. Marine and Petroleum Geology 19, 1029-1042.

Tesauro, M., Kaban, M.K, Cloetingh, S.A.P.L. 2008. EuCRUST-07: A new reference model for the European crust. Geophysical Research Letters 35, LO5313. 